\title{
Understanding caregiver judgments of infant pain: Contrasts of parents, nurses and pediatricians
}

\author{
Rebecca R Pillai Riddell PhD CPsych ${ }^{1,2}$, Rachel E Horton $M A^{1}$, Jessica Hillgrove $M A^{1}$, \\ Kenneth D Craig PhD RPsych ${ }^{3}$
}

RR Pillai Riddell, RE Horton, J Hillgrove, KD Craig. Understanding caregiver judgments of infant pain: Contrasts of parents, nurses and pediatricians. Pain Res Manage $2008 ; 13(6): 489-496$.

BACKGROUND: Research suggests that caregivers' beliefs pertaining to infant pain and which infant pain cues are perceived to be important play an integral role in pediatric pain assessment and management.

OBJECTIVES: Following a recent quasi-experimental study reporting on caregiver background and age differences in actual infant pain judgments, the present study clarified these findings by analyzing caregivers' pain beliefs and the cues they use to make pain assessments, and by examining how the wording of belief questions influenced caregivers' responses.

METHODS: After making pain judgments based on video footage of infants between two and 18 months of age receiving immunizations, parents, nurses and pediatricians were required to respond to questionnaires regarding pain beliefs and importance of cues.

RESULTS: Parents generally differed from pediatricians. Parents tended to have less optimal beliefs regarding medicating the youngest infants, were more influenced by question wording, and reported using many more cues when judging older infants than other caregiver groups. In terms of beliefs, influence of question wording and cue use, nurses tended to fall in between both groups; they displayed similarities to both parents and pediatricians.

CONCLUSIONS: Paralleling the original findings on pain judgments, these findings suggest that parents differ from pediatricians in their pain beliefs and the cues they use to make pain judgments. Moreover, some similarities were found between parents and nurses, and between nurses and pediatricians. Finally, caution must be taken when interpreting research pertaining to beliefs about infant pain because question wording appears to influence interpretation.

Key Words: Beliefs; Caregivers; Infant; Judgment; Pain

\section{Comment les soignants jugent-ils la douleur chez le nourrisson? Contraste entre parents, infirmières et pédiatres}

HISTORIQUE : Selon la recherche, les croyances des soignants au sujet de la douleur et de ses indices chez le nourrisson joueraient un rôle important dans leur façon de l'évaluer et de la traiter.

OBJECTIFS : À la suite d'une récente étude quasi-expérimentale sur le rôle du bagage et de l'âge des soignants dans l'opinion qu'ils se forment de la douleur réelle des nourrissons, la présente étude a voulu clarifier certains résultats en analysant les croyances des soignants sur la douleur et les indices utilisés pour l'évaluer et en examinant de quelle façon la formulation des questions sur ces croyances pouvait influer sur leurs réponses.

MÉTHODES : Après avoir évalué des épisodes douloureux montrés sur des segments vidéos de nourrissons de 2 à 18 mois qui recevaient des vaccins, des parents, des infirmières et des pédiatres ont été invités à répondre à des questionnaires sur leurs croyances relativement à la douleur et sur l'importance des indices.

RÉSULTATS : Les parents ont en général fourni des réponses différentes de celles de pédiatres. Ils ont eu tendance à adopter des positions moins optimales quant à l'administration des médicaments aux nourrissons plus jeunes; ils ont été davantage influencés par la formulation des questions et, comparativement aux autres groupes de soignants, ils ont indiqué utiliser un bien plus grand nombre d'indices pour évaluer la douleur chez les nourrissons plus âgés. Sur le plan des croyances, de l'influence de la formulation des questions et de l'utilisation des indices, les infirmières ont eu tendance à se situer entre les deux autres groupes. Elles ont présenté des similitudes avec les parents aussi bien qu'avec les pédiatres.

CONCLUSIONS : En établissant un parallèle entre les conclusions initiales et les présentes observations relativement à l'évaluation de la douleur, on est porté à croire que les parents entretiennent des croyances différentes de celles des pédiatres en ce qui concerne la douleur et les indices qu'ils utilisent pour l'évaluer. De plus, certaines similitudes ont été observées entre les parents et les infirmières et entre les infirmières et les pédiatres. En conclusion, la prudence s'impose lorsqu'on interprète les résultats de la recherche sur les croyances relatives à douleur chez les nourrissons, parce que la formulation des questions semble exercer une influence sur leur interprétation.

on the course of development $(4,5)$. Nevertheless, despite these substantial advances in understanding pediatric pain, infant pain remains undermanaged (6).

One of the challenges inherent to improving infant pain management practices has been reaching the different groups of caregivers who accept this responsibility, including parents, nurses and pediatricians (7-9). Because these caregivers differ in their knowledge, skills and experiences with infant pain, it follows that they are likely to use differing mental algorithms when assessing pain. Given the magnitude and variation of pain in infancy can have a detrimental and sustained impact

\footnotetext{
${ }^{1}$ York University; ${ }^{2}$ The Hospital for Sick Children, Toronto, Ontario; ${ }^{3}$ University of British Columbia, Vancouver, British Columbia

Correspondence: Dr Rebecca Pillai Riddell, Department of Psychology, York University, 119 Behavioural Sciences Building, 4700 Keele Street,

Toronto, Ontario M3J 1P3. Telephone 416-736-2100 ext 33204, fax 416-736-5814, e-mail rpr@yorku.ca
} 
information available to a caregiver and the inherent ambiguity of pain expression in a preverbal infant, decision-making is likely to depend on the use of heuristic concepts $(7,10)$. Prkachin et al (11) recently reviewed the heuristic processes that health professionals use when judging the pain of adult patients and found that factors such as evidence of pain and suspicions surrounding the motivations of the patient impacted pain judgments. This establishes the importance of caregivers' beliefs surrounding infant pain and the nonverbal cues they display when in pain as determinants of heuristic decisionmaking when confronted with the infant in pain.

\section{Caregivers' pain beliefs as factors underlying pain judgments}

A growing body of research indicates that caregivers' pain beliefs play an important role in the assessment and management of infant pain (12-15). McLaughlin et al (13) found that physicians who endorsed the belief that infants experience less pain than adults were more likely to perceive the administration of analgesia to infants as dangerous. In related work, Porter et al (16) found that nurses and physicians who endorse the belief that infants experience more pain than adults were more likely to sanction frequent administration of analgesics in addition to supporting nonpharmacological pain management practices.

While the impact of health professionals' pain beliefs on pediatric pain assessment and management have been demonstrated, the relationship between parents' pain beliefs and their assessment and management of infant pain is less clear, despite the pivotal role of parents in caring for infants. Parents have been shown to rate pain as being almost twice as severe for infants than for adults undergoing a hypothetically similar pain experience (17). In a study with older children (18), parents' personal satisfaction with past experiences of pain control was found to be more important in predicting willingness to deliver postoperative analgesics to their children than other variables directly related to their children's pain. Parents, in general, are reluctant to provide adequate analgesia to alleviate pain in infants and children (19), a tendency that may reflect the belief that the use of pediatric analgesics is dangerous (20).

While the literature investigating caregivers' pain beliefs has expanded, an inherent problem in the examination of these studies lies in variants of question wording $(12-14,16)$. We note, for example, that some questions concerning infant pain provide adult referents (eg, "At what age do you believe children can experience pain similar to adults?"), while others do not (eg, "At what age do you believe children can experience pain?"). In consequence, it is important to determine whether caregivers' pain beliefs differ as a function of how pain belief questions are formulated.

Infant pain cues as factors underlying infant pain judgment Overstated claims about self-report as the gold standard for measuring pain (21) made it difficult to recognize the importance of nonverbal expressions of pain in preverbal children and infants (2). However, nonverbal behaviour can provide reliable and valid evidence of pain (22-24). Most of the research examining how cues impact pain judgments has involved nurses. Nurses have more technical medical knowledge and would be expected to be more skilled in pain assessment than parents. In contrast to pediatricians, nurses typically spend more time with individual infants (25). Studies have found that nurses report using various infant states, and facial and body movements to assess pain (12,26-33). Seymour et al (34) found that nurses tended to repeatedly use certain cues; when taken together, crying, body movement and facial activity accounted for $92 \%$ of all pain cues used. However, other studies showed little consensus among participants about which cues indicated pain, with agreement ranging from $16 \%$ (30) to $50 \%$ (28). Seymour et al (34) found that the more experienced nurses were more selective in the number of cues they considered important when making pain judgments.

There is a paucity of research examining the impact of cues on pediatricians' pain judgments. Physicians typically possess the most specialized medical knowledge and are likely to see a greater number of different infants than nurses. This certainly is the case in comparison with parents (25). However, pediatricians typically spend little time with individual infants under their care. McLaughlin et al (13) found that physicians who endorsed the belief that infants experience less pain than adults were more likely to use fewer pain cues when assessing infant pain and were more likely to perceive the administration of pain medication as dangerous.

There is also little research examining how parents use infants' nonverbal cues to make their pain judgments. Given their personal investment and lack of technical knowledge about infant pain, parents face a more ambiguous, distressing and challenging task in assessing and managing their infant's pain compared with health care professionals (35). However, parents typically spend more time with their infant compared with nurses or pediatricians and come to know their children's idiosyncratic responses in a variety of contexts.

\section{PURPOSE}

The purpose of the present study was to examine caregivers' beliefs about pain in infants and the hierarchical importance of pain cues as they relate to actual infant pain judgments. Pillai Riddell and Craig (25) recently reported differences among the judgments of pain by parents, nurses and pediatricians after viewing the videotaped reactions of infants to an immunization injection. Older infants (18 months of age) were perceived to be in greater pain than younger infants (two months of age) by all caregivers, regardless of group. As well, parents as a group rated infant pain significantly higher than pediatricians, whereas nurses' ratings did not differ significantly from either group.

The present study examined whether the beliefs of these caregivers concerning infant pain were related to their judgments, using additional data collected during the study reported by Pillai Riddell and Craig (25). As well, given that a survey of the relevant literature $(13,14,16)$ revealed that studies vary in their wording of pain belief questions, a secondary purpose of the current study was to observe whether variations in questionnaire wording would influence caregivers' responses.

\section{METHOD}

\section{Participants}

A total of 123 participants were recruited for the original study (25), including 41 parents (34 mothers, seven fathers; mean age [ $\pm \mathrm{SD}] 39.61 \pm 7.60$ years), 41 nurses (41 women; mean age $37.95 \pm 8.80$ years) and 41 pediatricians (18 women, 23 men; mean age $45.68 \pm 9.28$ years). Parents were randomly selected 
from a pool of participants included in a previous study (17), nurses were recruited at the special care nursery of a tertiary children's hospital and pediatricians were recruited using the provincial registry of pediatricians. None of the parents included in the final sample were health professionals, while 22 nurses and 29 pediatricians were parents. Participants did not need to currently be the parent of an infant to be eligible for the study.

\section{Procedure}

Ethics approval for the present study was obtained from the University of British Columbia Research Ethics Board and Children's \& Women's Hospital Institutional Review Board. Data collection took place in one of three locations - a science museum (parents), a children's hospital special care nursery (nurses) or pediatricians' offices (pediatricians). The same study protocol was used across locations and caregiver groups. Each participant met alone with a research assistant in an enclosed room. Each participant signed a consent form and completed a written demographics questionnaire as well as the pain beliefs questionnaire. Caregivers were then asked to judge the pain apparent in videotaped reactions to routine immunizations in healthy infants from five different age groups (two, four, six, 12 and 18 months of age) (25). The video stimuli were selected from those provided by a larger sample of 75 infants from a previous study (36). Each videotape clip displayed an infant pain reaction with similar levels of behavioural pain reactivity and lasted exactly $10 \mathrm{~s}$ from the needle skin puncture (25). To control for the impact of viewing other adults' responses to the infant in pain, video clips were excluded if parental facial expressions were visible. All video clips of infants within an age group (two, four, six, 12 and 18 months of age) were viewed together with the presentation of age groups counterbalanced (five different orders were used, with four clips in each age group). In addition, participants were placed so they did not have a clear view of the experimenter's facial expression during the video judgment portion of the present study.

All participants were familiarized with the judgment protocol by practising on a sample video clip. After introduction to the study protocol, participants viewed a video clip of an infant reacting to an immunization and were immediately asked to provide a judgment of that infant's pain severity. Participants were allowed to take as long as needed to fill out the pain scales before viewing the next $10 \mathrm{~s}$ clip, but were only allowed to view each clip once. After judging all infants within an age group, caregivers were asked to complete a questionnaire on the importance of 12 cues to their judgments of pain for that age group of infants. Participation in the study, including the video judgments, did not typically exceed $30 \mathrm{~min}$.

It is important to note that in the present study, parents were not asked to judge pain severity in their own children. The children were those of other parents. To ensure a fair comparison among caregiver groups, none of the three caregiver groups had previous experience with the infants in the videos and all caregivers had precisely the same exposure to the video stimuli. Moreover, to control for the influence of differing infant pain reactivity across the age groups, videotapes in the different age groups were selected to ensure all infants expressed similar levels of pain (25).

\section{Measures}

Pain belief questions: Based on precedents in the literature, four questions addressing beliefs about the nature of infant pain $(12-14,16,29,30,37)$ were posed to the caregivers. The pain belief questions were answered before the video judgment phase. Three questions concerned infant age and pain - "At what age do you believe children experience pain similar to adults?", "At what age do you believe children can experience pain?" and "At what age do you believe children can experience pain as intensely as adults?" Questions 1, 2 and 3 permitted examination of how variants in question wording may impact caregivers' responses. The fourth question addressed the pharmacological management of pediatric pain - "At what age do you believe it is appropriate to begin to administer a painrelieving medication?" Caregivers were asked to respond to each question on a six-point scale where 1 = 'birth -1 month', $2=$ ' $1-4$ months', 3 = ' $4-8$ months', 4 = ' $8-12$ months', 5 = ' $12-18$ months' and $6=$ ' 18 months +'.

The importance of cues questionnaire: This questionnaire was developed to assess the relative importance of different cues used to understand pain in infants (10). A review of the literature revealed no measure that quantitatively examined this construct. The importance of cues questionnaire elicits ratings of the importance of 12 common cues in judgments of pain that were reviewed in the literature to date. Participants were asked to rate each cue on a scale of 0 ('not at all important') to 10 ('extremely important'). The 12 cues were the infants' capacity to focus on their surroundings, the infants' age, size, facial expressions, sounds, mood, body movements, whether the infants were in a medical setting, the fact that the infants had just received a needle, the infants were healthy, the infants' capacity to understand pain and capacity to remember pain. Caregivers were provided with space in which to write and rate other cues that they felt were important to their pain judgments, but were not included in the questionnaire. One response was added but was not analyzed due to its rarity and reported lack of importance.

\section{Data analysis}

\section{RESULTS}

Descriptive statistics: Demographic characteristics (including age, ethnicity and parental status) were compared across the three caregiver groups by Pillai Riddell and Craig (25). Findings are summarized here because these analyses inform the current study. A one-way ANOVA and Tukey's post hoc procedure revealed that pediatricians were significantly older than parents and nurses $\left(\mathrm{F}_{[2,120]}=9.20, \mathrm{P}<0.001\right)$. A $\chi^{2}$ analysis revealed that identified ethnicity did not differ significantly among caregiver groups (of the final sample, $80.49 \%$ of participants identified themselves as 'Caucasian', 13.82\% as 'Asian' and $5.69 \%$ as 'other'), while pediatricians were more likely to be male $(n=23)$ than nurses $(n=0)$ or parents $(n=7)\left(\chi^{2}{ }_{[2]}=36.77\right.$, $\mathrm{P}<0.001)$. Finally, as would be expected, $\chi^{2}$ analysis revealed that, while 22 nurses and 29 pediatricians were parents, there were significantly more parents in the parent caregiver group $\left(\chi_{[2]}^{2}=23.89, \mathrm{P}<0.001\right)$.

Caregivers' responses to belief questions: The $\chi^{2}$ analyses compared caregiver groups in terms of their responses to the four questions of interest. Caregivers' responses were dichotomized into 'birth - 1 month' (ie, endorsement of response 1) 
TABLE 1

Distribution of caregivers' responses to pain beliefs questions

\begin{tabular}{|c|c|c|c|c|}
\hline Question & Response & $\begin{array}{c}\text { Parents } \\
(n=41)\end{array}$ & $\begin{array}{c}\text { Nurses } \\
(n=41)\end{array}$ & $\begin{array}{c}\text { Pediatricians } \\
\quad(n=41)\end{array}$ \\
\hline \multirow{3}{*}{$\begin{array}{l}\text { 1. At what age do you } \\
\text { believe children can } \\
\text { experience pain similar } \\
\text { to adults?* }\end{array}$} & From birth & 25 & 35 & 36 \\
\hline & $\begin{array}{l}\text { Older than } \\
1 \text { month }\end{array}$ & 14 & 6 & 3 \\
\hline & $\begin{array}{c}\text { No response } \\
\text { provided }\end{array}$ & 2 & 0 & 2 \\
\hline \multirow{3}{*}{$\begin{array}{l}\text { 2. At what age do you } \\
\text { believe children can } \\
\text { experience pain? }\end{array}$} & From birth & 34 & 39 & 41 \\
\hline & $\begin{array}{l}\text { Older than } \\
1 \text { month }\end{array}$ & 5 & 2 & 0 \\
\hline & $\begin{array}{c}\text { No response } \\
\text { provided }\end{array}$ & 2 & 0 & 0 \\
\hline \multirow{3}{*}{$\begin{array}{l}\text { 3. At what age do you } \\
\text { believe children can } \\
\text { experience pain as } \\
\text { intensely as adults?* }\end{array}$} & From birth & 22 & 35 & 33 \\
\hline & $\begin{array}{l}\text { Older than } \\
1 \text { month }\end{array}$ & 16 & 4 & 8 \\
\hline & $\begin{array}{c}\text { No response } \\
\text { provided }\end{array}$ & 3 & 2 & 0 \\
\hline \multirow{3}{*}{$\begin{array}{l}\text { 4. At what age do you } \\
\text { believe it is appropriate } \\
\text { to begin to administer a } \\
\text { pain-relieving medica- } \\
\text { tion?** }\end{array}$} & From birth & 24 & 38 & 40 \\
\hline & $\begin{array}{l}\text { Older than } \\
1 \text { month }\end{array}$ & 14 & 3 & 1 \\
\hline & $\begin{array}{c}\text { No response } \\
\text { provided }\end{array}$ & 3 & 0 & 0 \\
\hline
\end{tabular}

*Significant at $P<0.05$; **significant at $P<0.001$

and 'older than 1 month' (ie, endorsement of responses 2, 3, 4, 5 or 6 ) because the distribution of responses across the categories above ' 1 ' resulted in empty cells. Moreover, the distinction between infants who are younger or older than one month of age is conceptually sound because it marks the end of the perinatal period, with infants younger than one month of age considered neonates (38). A summary of the distribution of caregivers' responses is depicted in Table 1.

Question 1: At what age do you believe children experience pain similar to adults? Significantly more parents than nurses or pediatricians answered that infants only experience pain similar to adults after one month of age (Table $1 ; \chi_{[2]}^{2}=8.44$, $\mathrm{P}<0.05$ ). Two parents and two pediatricians did not provide a response to this question.

Question 2: At what age do you believe children can experience pain? The number of parents, nurses and pediatricians who responded that children can experience pain from birth or after one month of age was not found to be statistically different (Table 1). Two parents did not provide a response to this question.

Question 3: At what age do you believe children can experience pain as intensely as adults? Significantly more parents than nurses or pediatricians answered that infants experience pain as intensely as adults after one month of age (Table 1 ; $\left.\chi_{[2]}^{2}=8.00, P<0.05\right)$. Three parents and two nurses did not provide a response to this question.

Question 4: At what age do you believe it is appropriate to begin to administer a pain-relieving medication? Significantly more parents than nurses or pediatricians answered that it is only appropriate to begin to administer a pain-relieving medication after one month of age (Table $1 ; \chi_{[2]}^{2}=4.47, \mathrm{P}<0.001$ ). Three parents did not provide a response to this question.
TABLE 2

Multivariate ANOVA on importance of cues ratings for twomonth-olds: Means \pm SDs for follow-up comparisons

\begin{tabular}{|c|c|c|c|}
\hline & \multicolumn{3}{|c|}{2 months } \\
\hline & Parent & Nurse & Pediatrician \\
\hline Age & - & - & - \\
\hline Sounds* & $8.93 \pm 1.65^{a}$ & $7.80 \pm 1.62^{b}$ & $7.32 \pm 2.17^{b}$ \\
\hline $\begin{array}{l}\text { Capacity to } \\
\text { understand pain }\end{array}$ & - & - & - \\
\hline $\begin{array}{l}\text { Capacity to } \\
\text { remember pain }\end{array}$ & - & - & - \\
\hline Size & - & - & - \\
\hline $\begin{array}{l}\text { Infant in a medical } \\
\text { setting }\end{array}$ & - & - & - \\
\hline Facial expression & $8.46 \pm 2.47$ & $8.54 \pm 1.23$ & $7.89 \pm 1.75$ \\
\hline $\begin{array}{l}\text { Infant just } \\
\text { received a } \\
\text { needle }\end{array}$ & $6.41 \pm 3.63$ & $7.73 \pm 2.75$ & $6.49 \pm 3.18$ \\
\hline Mood & - & - & - \\
\hline Body movements* & $7.71 \pm 2.88^{a}$ & $7.78 \pm 1.73^{a}$ & $6.32 \pm 2.48^{b}$ \\
\hline Infant was healthy & $4.05 \pm 3.99$ & $5.07 \pm 3.30$ & $3.24 \pm 3.22$ \\
\hline $\begin{array}{l}\text { Capacity to focus } \\
\text { on its surround- } \\
\text { ings }\end{array}$ & - & - & - \\
\hline
\end{tabular}

$\overline{\text { Judgments were made on a 11-point scale }(0=\text { not important, } 5=\text { moderately }}$ important, 10 = extremely important). Dashes within the table indicate that the cue did not meet criteria to be entered in the multivariate ANOVA (it did not have at least one group with a mean importance rating greater than 5). Means having the same superscript are not significantly different at $P<0.02$ using the Tukey honestly significantly different comparison (ie, all values marked with a superscript ' $a$ ' are not significantly different from each other at $P<0.02$ ). ${ }^{*}$ Follow-up one-way ANOVA significant at $P<0.01$

Importance of cues ratings

Analyses of ratings of the relative importance of cues were conducted for the youngest (two months) and the oldest (18 months) groups. The purpose was to examine which cues were most important to each group of caregivers and if there were any group differences in these cues for the youngest (two months) versus oldest (18 months) infants depicted in the videos. Only two of the age groups observed were chosen for this analysis to compare cues across the two extreme age groups and to reduce the number of statistical tests.

\section{Cues of greatest importance}

Cues on the questionnaire for which at least one group of caregivers had a mean importance rating greater than 5 (ie, cues rated as 'moderately' to 'extremely' important) were examined for between-group differences. Caregivers rated five cues of moderate or greater importance when evaluating the pain of two-month-olds (Table 2), while 11 cues were rated as moderately or more important when evaluating the pain of 18-montholds (Table 3). A tally of the number of cues rated as moderately important or greater for the two-month-olds revealed no differences among the three groups of caregivers (ie, 'sounds', 'facial expressions', 'body movements', 'the infant had just received a needle' and 'the health of the infant' were all consistently rated as most important by all three groups of caregivers, although in varying order of importance). However, while pediatricians rated the same four cues as moderately or more important in 
Beliefs underlying infant pain judgments

TABLE 3

Multivariate ANOVA on importance of cues ratings for 18-month-olds: Means \pm SDs for follow-up comparisons

\begin{tabular}{|c|c|c|c|}
\hline & \multicolumn{3}{|c|}{18 months } \\
\hline & Parent & Nurse & Pediatrician \\
\hline Age & $5.85 \pm 3.90$ & $5.00 \pm 3.53$ & $3.61 \pm 3.06$ \\
\hline Sounds* & $8.56 \pm 1.92^{\mathrm{a}}$ & $7.76 \pm 1.71^{\mathrm{ab}}$ & $6.90 \pm 2.29^{b}$ \\
\hline $\begin{array}{l}\text { Capacity to under- } \\
\text { stand pain }\end{array}$ & $5.95 \pm 3.40$ & $5.71 \pm 3.32$ & $4.7805 \pm 2.86$ \\
\hline $\begin{array}{l}\text { Capacity to } \\
\text { remember pain }\end{array}$ & $5.61 \pm 3.51$ & $5.61 \pm 3.32$ & $4.00 \pm 3.22$ \\
\hline Size & - & - & - \\
\hline $\begin{array}{l}\text { Infant was in a } \\
\text { medical setting }\end{array}$ & $5.00 \pm 3.27$ & $5.29 \pm 2.85$ & $4.07 \pm 2.76$ \\
\hline Facial expressions & $8.71 \pm 1.91$ & $8.39 \pm 1.50$ & $7.63 \pm 2.11$ \\
\hline $\begin{array}{l}\text { Infant had just } \\
\text { received a } \\
\text { needle }\end{array}$ & $6.88 \pm 3.49$ & $7.49 \pm 2.90$ & $6.73 \pm 3.15$ \\
\hline Mood & $6.02 \pm 3.42$ & $5.12 \pm 2.87$ & $4.71 \pm 2.49$ \\
\hline Body movements* & $8.10 \pm 2.36^{\mathrm{a}}$ & $7.54 \pm 2.19^{a}$ & $6.17 \pm 2.42^{b}$ \\
\hline Infant was healthy & $4.63 \pm 3.97$ & $5.18 \pm 3.48$ & $3.05 \pm 2.94$ \\
\hline $\begin{array}{l}\text { Capacity to focus } \\
\text { on their sur- } \\
\text { roundings }\end{array}$ & $5.71 \pm 3.74$ & $5.39 \pm 3.14$ & $4.59 \pm 2.90$ \\
\hline
\end{tabular}

Judgments were made on a 11-point scale $(0=$ not important, $5=$ moderately important, $10=$ extremely important). Dashes within the table indicate that the cue did not meet criteria to be entered in the multivariate ANOVA analysis (at least one sample with a mean importance rating greater than 5). Means having the same superscript are not significantly different at $P<0.02$ in the Tukey honestly significant difference comparison (ie, all values marked with a superscript ' $a$ ' are not significantly different from each other at $P<0.02)$. *Follow-up one-way ANOVA significant at $P<0.001$

their assessments of two-month-old and 18-month-old infants, nurses and parents rated a greater number of cues as being moderately or more important when assessing 18-month-old infants than when assessing two-month-old infants.

Two multivariate ANOVAs (MANOVAs) on the importance ratings of cues for the two- and 18-month-olds were conducted using a family-wise error rate of 0.05 (0.025 for each test). Assumptions for both MANOVAs were examined and considered met. Wilks' lambda was employed because this multivariate test has good power and is most commonly used for multivariate analyses (39). Both the MANOVA for the two-month-olds $\left(\mathrm{F}_{[10,232]}=2.90, \mathrm{P}<0.002\right.$; Table 2) and the MANOVA for the 18-month-olds $\left(\mathrm{F}_{[22,218]}=2.26, \mathrm{P}<0.002\right.$; Table 3) were significant. A series of one-way ANOVAs and Tukey's post hoc comparisons followed up the significant omnibus MANOVAs. For each group of follow-up comparisons, a family-wise error rate of 0.10 was used for both the one-way ANOVAs and the Tukey's post hoc comparisons. Post hoc analyses for the cues used for the two- and 18-month-olds found that ratings of 'sounds' and 'body movements' always distinguished the parents from either one or two of the health professional groups.

Importance ratings that optimally distinguish caregiver groups

For both the two- and 18-month-old groups, the importance ratings of all 12 cues from the questionnaire were examined
TABLE 4

Discriminant function analyses of importance ratings of cues: Standardized discriminant function coefficients for both analyses

\begin{tabular}{lcc}
\hline & 2-month-olds & 18-month-olds \\
\hline Age & 0.586 & 0.315 \\
Sounds & 0.882 & 0.332 \\
Understanding & -0.145 & -0.549 \\
Memory & 0.001 & 0.491 \\
Size & 0.300 & 0.429 \\
Medical setting & -0.436 & 0.150 \\
Facial expressions & -0.504 & -0.171 \\
Needle & -0.421 & -0.359 \\
Mood & 0.174 & -0.386 \\
Body movements & 0.232 & 0.732 \\
Health & 0.227 & 0.370 \\
Surroundings & -0.223 & -0.125 \\
\hline
\end{tabular}

\section{TABLE 5}

Group centroids for the primary discriminant function on importance ratings for 2-month-olds and 18-month-olds

\begin{tabular}{lcc}
\hline & 2-month-olds & 18-month-olds \\
\hline Parents & 0.772 & -0.822 \\
Nurses & -0.244 & 0.436 \\
Pediatricians & -0.503 & 0.396 \\
\hline
\end{tabular}

simultaneously to analyze the overall pattern of how each group of caregivers rated all the cues. Discriminant function analysis (DFA) is a procedure that sets out to find dimensions along which groups differ. Each dimension can be referred to as a discriminant function. In applied terms, a discriminant function is a new variable that has been created from a set of variables optimally weighted to maximize discrimination between groups.

The DFA for the two-month-olds indicated that the first discriminant function was significant $\left(\chi_{[24]}^{2}=47.66, \mathrm{P}<0.003\right)$ and accounted for $63.8 \%$ of the total discrimination among the three groups (Table 4). From analyzing the discriminant function coefficients, it was deduced that the importance ratings of 'sounds', 'age', 'medical setting', 'facial expression' and the fact that 'the infants had just received a needle' were weighted most heavily in the discriminant function (ie, the importance ratings of these cues distinguished the three groups best). Parents scored highest on this discriminant function variable and tended to rate 'sounds' and 'age' of greater importance, and 'medical setting', 'facial expression' and the fact that the 'infants had just received a needle' of lesser importance than the other two caregiver groups. By examining the group centroids on the discriminant function, it is evident that they reliably discriminated the parents from both nurses and pediatricians (Table 5).

The DFA for the 18-month-olds also indicated that the first discriminant function was significant $\left(\chi^{2}{ }_{[24]}=52.83\right.$, $\mathrm{P}<0.001)$ and accounted for $66.2 \%$ of the total discrimination among the groups (Table 4). The discriminant function 
coefficients suggested that the importance ratings of 'body movements', 'infant ability to remember pain', 'infant size' and 'infant ability to understand pain' were key elements for discriminating among the three caregiver groups. Parents tended to rate 'understanding' as more important, while the 'body movements', 'remembering' and 'size' cues tended to be rated as being less important by parents than health professionals. Again, the centroids of this function reliably discriminated parents from both nurses and pediatricians (Table 5).

\section{DISCUSSION}

The present study set out to contextualize earlier findings that parents' infant pain ratings were greater than pediatricians' pain ratings, while nurses' ratings were found to fall between these two groups of caregivers. Older infants were consistently rated as having more pain than younger infants by all three groups of caregivers (25). In the present study, pain beliefs and the relative importance of infant pain cues when making pain assessments as reported by the caregivers were examined. A secondary goal of the present study was to examine whether variations in pain belief question wording had an impact on caregivers' responses.

\section{Caregivers' responses to pain belief questions}

In terms of caregivers' pain beliefs, parents were found to differ significantly from nurses and pediatricians both in terms of beliefs surrounding the infants' pain experience and the management of infant pain. Specifically, significantly more parents than health professionals endorsed the position that infants begin to experience pain similar to or as intensely as adults after one month of age, rather than from birth. Moreover, significantly more parents than health professionals reported that it would only be appropriate to administer a pain-relieving medication after one month of age. In comparison with health professionals, parents appear to lack knowledge of infant pain and infant pain management, leading to more conservative beliefs regarding pain in infants younger than one month of age (25). In line with our findings, parents have reported feeling underinformed about the management of their children's pain (40). Parents' hesitation or reluctance to provide analgesia for infants from birth may be due to their potentially misplaced alarm about the consequences of potent medications for infants $(41-44)$. Franck et al $(41,42)$ and Gale et al $(43)$ have shown that parents report strong emotional connections with their children when they are undergoing painful medical procedures and that parents perceive their children's pain as a source of worry, helplessness and fear - factors which may increase anxiety surrounding pharmacological pain management. Taken together, our findings indicate that parents' beliefs regarding the pain experience of neonates and the inappropriateness of pain medication differ qualitatively from those of health professionals. These differences may account for their willingness to attribute higher pain ratings to the infants.

\section{Variants in pain belief question wording}

Noting that researchers tend to ask participants about their belief in infant pain in different ways, the caregivers in the present study were asked about infant pain experiences in three different ways (based on precedents in the literature). Only parents' responses regarding beliefs about infant pain experience were influenced by variants of question wording. When asked "At what age do you believe children can experience pain?" the proportion of parents, nurses and pediatricians who selected each answer did not differ, with the overwhelming majority of all three caregiver groups indicating that they believe infants can experience pain from birth. Differences in pain beliefs regarding infant pain experience emerged, however, when questions included an adult referent (ie, "similar to adults" or "as intensely as adults"). While parents, nurses and pediatricians were equally likely to endorse the response that infants experience pain from birth when no adult referent was included, a significantly greater proportion of parents endorsed the response that infants do not begin to experience pain in a "similar" way or as "intensely" as adults until after one month of age. Nurses and pediatricians did not show any difference in their responses based on the presence or absence of an adult referent. This finding suggests that research examining pain beliefs relating to the infant pain experience must interpret subjects' responses with caution because subtle differences in wording seem to elicit different responses for certain caregivers. Parents had the least infant pain-related experience of the three samples and this lack of experience may have caused them to more carefully distinguish between the questions posed.

\section{Cues of greatest importance}

Pediatricians' pain ratings consistently differed from parents' ratings when examining individual cues. All three caregiver groups were remarkably similar in rating 'sounds', 'facial expressions', 'body movements' and the fact that the 'infants had just received a needle' as being of highest importance when providing pain assessments of two- and 18-month-olds. Assigning importance to these cues was consistent with other studies in this area of research $(28,33,45)$. However, pediatricians rated the same four cues as being most important to their pain judgments regardless of infant age, whereas nurses and parents rated more cues as important to their pain judgments for 18-montholds relative to two-month-olds. These findings imply that pediatricians differ in their heuristic framework from parents and nurses when judging infant pain. Pediatricians may have a more economical heuristic structure than both nurses and parents. Given that pediatricians spend the least time with a given patient and see more patients overall, this structure may have developed due to the different nature of their clinical demands.

\section{Interpreting cue importance ratings simultaneously}

Even with optimal weighting, it appears that the nurses and pediatricians did not differ significantly in their importance ratings of the set of 12 cues for the two- or 18-month-olds, while parents differed consistently from the health professionals for both age groups.

With regard to the group differences that were found, for two-month-olds the discriminant function was based mostly on importance ratings of environmental or objective cues (ie, 'sounds', 'age', 'facial expression', 'needle' and 'medical setting'). For 18-month-olds, more subjective cues requiring inference into the infant's cognitive abilities contributed to optimal discrimination of the groups (ie, 'remembering pain' and 'understanding pain'). Thus, it appears that different cues were 
involved in distinguishing parents from health professionals for the two-month-olds versus the 18 -month-olds. This pattern of differences suggests that the perceived cognitive ability of the infant is a factor involved in age group differences in pain attributions.

\section{Clinical implications}

The present study demonstrated empirically that caregiver beliefs and the cues caregivers use to make pain judgments play an important role in understanding differences across caregivers' infant pain assessments. The findings suggest several avenues for improving pain management for infants and very young children. There may be an important relationship between parental tendencies to perceive infant pain as more intense than health professionals and their endorsement of beliefs about the infant pain experience or management. It is noteworthy that despite their higher pain ratings, parents had significantly more hesitation with pharmacological management in the neonatal period, and the comparison of neonate and adult pain processing, than the other caregiver groups. These combined findings suggest that efforts are needed to educate and empower parents in pharmacological pediatric pain management. Educational materials, such as instructional videotapes (46), have proven effective in increasing parents' knowledge about assessment and management of infant pain and may be adapted to target specific myths regarding infant pain experiences. Moreover, because nurses and parents gave similar pain judgments and used a similar amount of cues when making their pain judgments (regardless of infant age), it would behoove parent educators to look to the extensive nursing literature on understanding and improving clinical decision-making.

By elucidating the nature of how pain judgments are made by different caregivers, a better understanding of why different caregivers respond the way they do in the pain assessment context has been accomplished in the present study. By being better able to describe how caregivers make their pain judgments, specific heuristics can be targeted to correct erroneous beliefs that caregivers may have regarding infant pain and pain management that evidently play a role in the assessment of infant pain.

\section{Limitations}

Pediatricians in the present study were more likely to be men and were significantly older than nurses and parents. Although this is changing, this reflects the current composition of practicing pediatricians in Canada. There is a possibility that age or sex may impact caregivers' pain beliefs; however, previous analyses of pain judgments (continuous variable) demonstrated that these demographic differences were not consequential.

\section{REFERENCES}

1. Fitzgerald M. The development of nociceptive circuits. Nat Rev Neurosci 2005;6:507-20.

2. Anand KJS, Craig KD. Editorial: New perspectives on the definition of pain. Pain 1996;67:3-6.

3. Fitzgerald M, Beggs S. The neurobiology of pain: Developmental aspects. Neuroscientist 2001;7:246-57.

4. Mitchell A, Boss BJ. Adverse effects of pain on the nervous systems of newborns and young children: A review of the literature. J Neurosci Nurs 2002;34:228-36.

5. Taddio A, Katz J, Ilersich AL, Koren G. Effect of neonatal circumcision on pain response during subsequent routine vaccination. Lancet 1997;349:599-603.
Moreover, while previous studies have not found significant relationships between age and the nature of nurses' pain beliefs $(47,48)$, the effect of age and sex on the beliefs of parents and pediatricians requires further scrutiny.

The present study did not assess the actual pain management practices of parents, nurses or pediatricians, which limits the ability to draw conclusions about how caregivers' pediatric pain beliefs and infant pain ratings relate to actual pain management. While some parents and most health professionals endorse the administration of analgesia in infants from birth, conclusions regarding actual pain management practices cannot be drawn. Further research is needed to examine caregivers' pain beliefs, pediatric pain ratings and actual pediatric pain management practices concurrently to further confirm this relationship.

Finally, to test the veracity of the caregivers' reports regarding cue use, further research that manipulates the stimuli presented to the caregivers (depicting variations in cues) would be a valuable line of inquiry to determine how accurate caregivers were when reporting what was important to their judgments.

In spite of these limitations, the present study is the first to directly compare three groups of caregivers in regard to their pain beliefs and the importance of certain cues to their infant pain ratings. It lays the foundation for future investigations of caregivers' pain beliefs, pain assessments and pain management practices.

\section{CONCLUSIONS}

Previous work found that pediatricians attributed significantly less pain to infants than parents, while nurses did not differ from either sample; all three groups attributed more pain to older infants. The follow-up analyses of the present study suggest that the pain rating differences paralleled differences in pain beliefs and the perceived importance of infant pain cues across caregiver groups. While parents were almost always different than pediatricians in their beliefs and cue use, nurses tended to represent an intermediate position - sometimes their responses were similar to those of the pediatricians, and sometimes their responses were similar to those of the parents. Due to the experimental controls used in the present study, it provides novel insights into the nature of how different caregivers make their pain judgments and encourages future research on this topic.

ACKNOWLEDGEMENTS: The authors thank the caregivers who participated in the present study. Drs Pillai Riddell and Craig acknowledge CIHR and SSHRC for contributions to the project through salary support and operating grant funds that originated at The University of British Columbia, Vancouver, British Columbia. 
10. Pillai Riddell RRE. Attributions of pain to infants: A comparative analysis of parents, nurses and paediatricians. Dissertation, University of British Columbia, 2004.

11. Prkachin KM, Solomon PE, Ross J. Underestimation of pain by health-care providers: Towards a model of the process of inferring pain in others. Can J Nurs Res 2007;39:88-106.

12. Franck LS. A national survey of the assessment and treatment of pain and agitation in the neonatal intensive care unit. JOGN Nurs 1987;16:387-93.

13. McLaughlin CR, Hull JG, Edwards WH, Cramer CP, Dewey WL. Neonatal pain: A comprehensive survey of attitudes and practices. J Pain Symptom Manage 1993;8:7-16.

14. Schechter NL, Allen D. Physicians' attitudes toward pain in children. J Dev Behav Pediatr 1986;7:350-4.

15. Simons J, Roberson E. Poor communication and knowledge deficits: Obstacles to effective management of children's postoperative pain. J Adv Nurs 2002;40:78-86.

16. Porter FL, Wolf CM, Gold J, Lotsoff D, Miller JP. Pain and pain management in newborn infants: A survey of physicians and nurses. Pediatrics 1997 100:626-32.

17. Pillai Riddell RR, Badali MA, Craig KD. Parental judgments of infant pain: Importance of perceived cognitive abilities, behavioural cues and contextual cues. Pain Res Manage 2004;9:73-80.

18. Pillai Riddell RR, Lilley CM, Craig KD. Predicting parental attitudes toward the helpfulness of postoperative analgesic medication. Child Health Care 2004;33:185-200.

19. Finley GA, McGrath PJ, Forward SP, McNeill G, Fitzgerald P. Parents' management of children's pain following 'minor' surgery. Pain 1996;64:83-7.

20. Kankkunen P, Vehvilainen-Julkunen K, Pietila A, Kokki H, Halonen P. Parents' perceptions and use of analgesics at home after children's day surgery. Paediatr Anaesth 2003;13:132-40.

21. von Baeyer CL, Sagrud LJ. Systematic review of observational (behavioral) measures of pain for children and adolescents aged 3 to 18 years. Pain 2007;127:140-50.

22. Craig KD, Pillai Riddell R. Social influences, culture \& ethnicity. In: Finley GA, McGrath PJ, eds. The Context of Paediatric Pain: Biology, Family, Society and Culture. Seattle: IASP Press, 2003:159-82.

23. Hummel P, van Dijk M. Pain assessment: Current status and challenges. Semin Fetal Neonatal Med 2006;11:237-45.

24. Stevens B, Pillai Riddell RR, Oberlander T, Gibbins S. Assessment of pain in neonates and infants. In: Pain in Neonates and Infants, 3rd edn. Edinburgh: Elsevier Limited, 2007.

25. Pillai Riddell RR, Craig KD. Judgments of infant pain: The impact of caregiver identity and infant age. J Pediatr Psychol 2007;32:501-11.

26. Elander G, Lindberg T, Quarnstrom B. Pain relief in infants after surgery: A descriptive study. J Pediatr Surg 1991;26:128-31.

27. Hultgren MS. Assessment of postoperative pain in critically ill infants. Prog Cardiovasc Nurs 1990;5:104-12.
28. Jones MA. Identifying signs that nurses interpret as indicating pain in newborns. Pediatr Nurs 1989;15:76-9.

29. Page GG, Halvorson M. Paediatric nurses: The assessment and control of pain in preverbal infants. J Pediatr Nurs 1991;6:99-106.

30. Pigeon HM, McGrath PJ, Lawrence J, MacMurray SB. Nurses' perceptions of pain in the neonatal intensive care unit. J Pain Symptom Manage 1989;4:179-83.

31. Pomietto M. Pain management at Children's Hospital: Results of 1987 survey. Express 1988;3:1-4.

32. Fuller BF. Infant behaviors as indicators of established acute pain. Philadelphia: Nursecom, 2001.

33. Howard VA, Thurber FW. The interpretation of infant pain: Physiological and behavioral indicators used by NICU nurses. J Pediatr Nurs 1998;13:164-74.

34. Seymour E, Fuller BF, Pedersen-Gallegos L, Schwaninger JE. Modes of thought, feeling and action in infant pain assessment by pediatric nurses. J Pediatr Nurs 1997;12:32-50.

35. Pillai Riddell RR, Chambers CT. Parenting and pain during infancy. In: Anand KJ, Stevens BJ, McGrath BJ, eds. Pain in Neonates and Infants, 3rd edn. Amsterdam: Elsevier, 2007.

36. Lilley CM, Craig KD, Grunau RVE. The expression of pain in infants and toddlers: Developmental changes in facial action. Pain 1997;72:161-70.

37. Broome ME, Richtsmeier A, Maikler V, Alexander M. Paediatric pain practices: A national survey of health professionals. J Pain Symptom Manage 1996;11:312-20.

38. International Classification of Diseases, 9th Revision, Clinical Modification (ICD-9-CM). Hyattsville: National Center for Health Statistics, 2005.

39. Tabachnick BG, Fidell LS. Using Multivariate Statistics, 4th edn. Boston: Allyn and Bacon, 2001.

40. Franck LS, Cox S, Allen A, Winter I. Parental concern and distress about infant pain. Arch Dis Child Fetal Neonatal Ed 2004;89:F71-5.

41. Franck LS, Allen A, Cox S, Winter I. Parents' views about infant pain in neonatal intensive care. Clin J Pain 2005;21:133-9.

42. Franck LS, Scurr K, Couture S. Parent view of infant pain and pain management in the neonatal intensive care unit. Newborn Infant Nurs Rev 2001;1:106-13.

43. Gale G, Franck LS, Kools S, Lynch M. Parents' perceptions of their infant's pain experience in the NICU. Int J Nurs Stud 2004;41:51-8.

44. Tourigny J. État émotionnel des mères et comportement de l'enfant lors d'une chirurgie mineure. Can J Nurs Res 1992;24:65-80.

45. Fuller B, Thomson M, Conner DA, Scanlan J. Relationship of cues to assessed infant pain level. Clin Nurs Res 1996;5:43-66.

46. Greenberg RS, Billett C, Zahurak M, Yaster M. Videotape increases parental knowledge about paediatric pain management. Anesth Analg 1999;89:899-903.

47. Margolius FR, Hudson KA, Michel Y. Beliefs and perceptions about children in pain: A survey. Pediatr Nurs 1995;21:111-5.

48. Salantera S. Finnish nurses' attitudes to pain in children. J Adv Nurs 1999;29:727-36. 


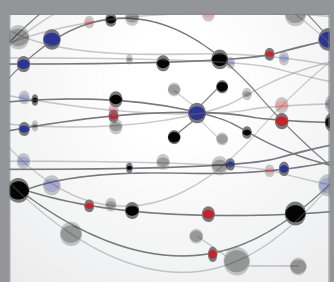

The Scientific World Journal
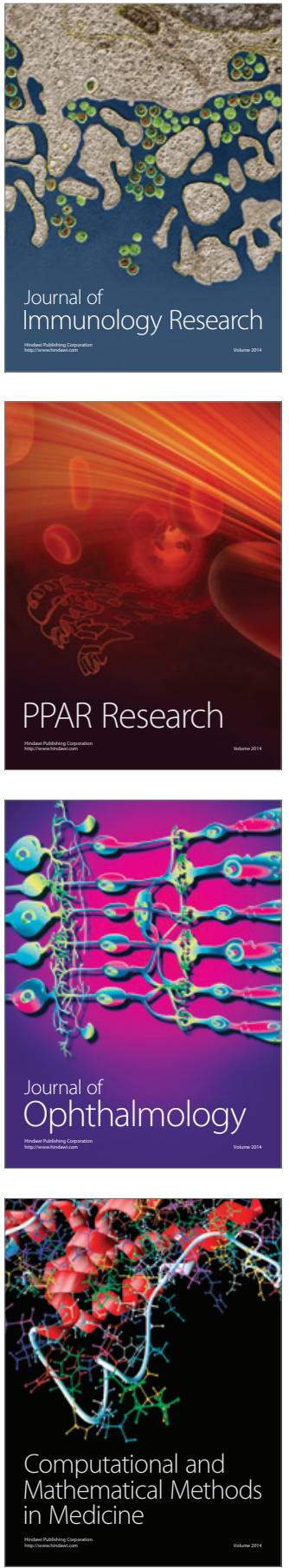

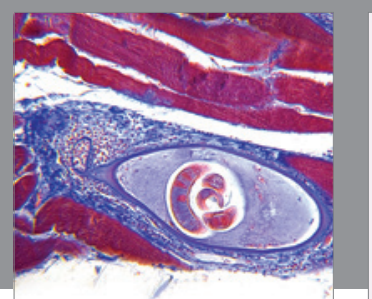

Gastroenterology Research and Practice

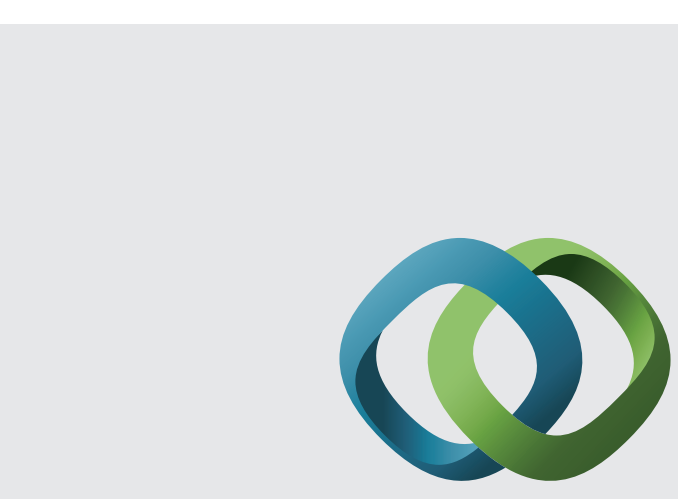

\section{Hindawi}

Submit your manuscripts at

http://www.hindawi.com
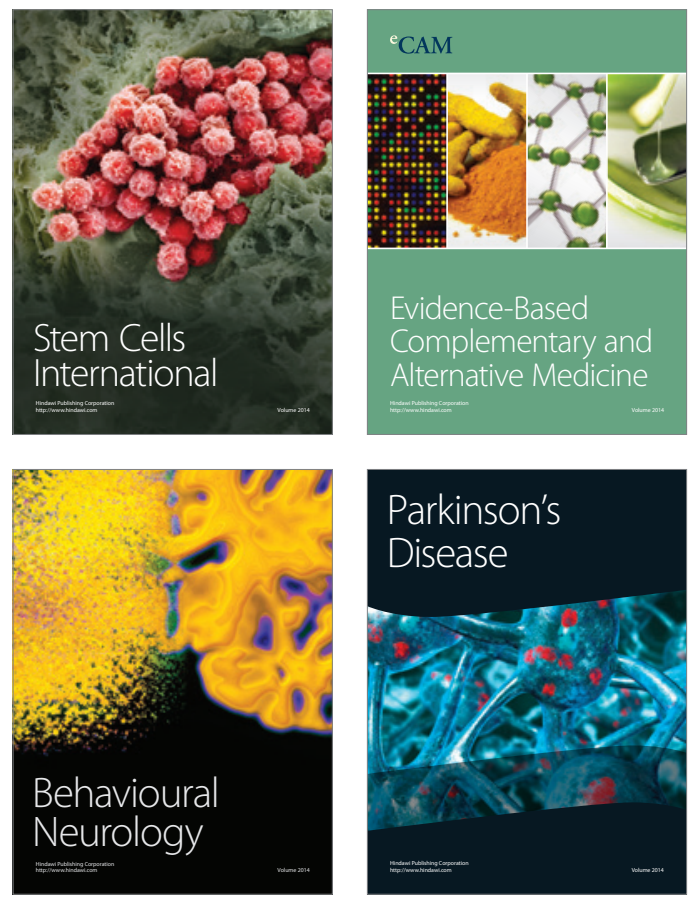
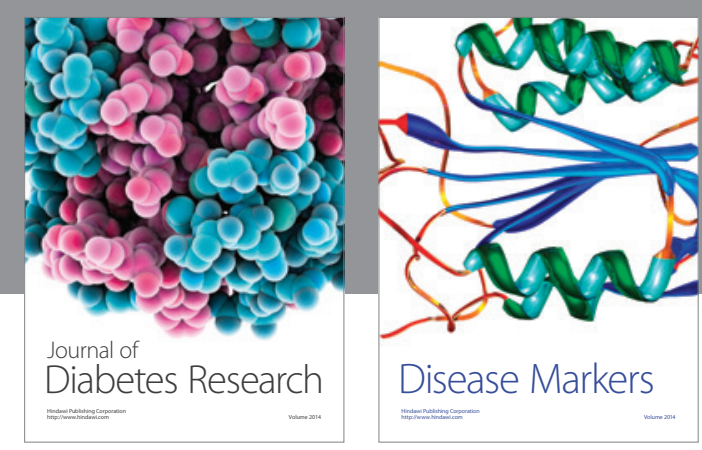

Disease Markers
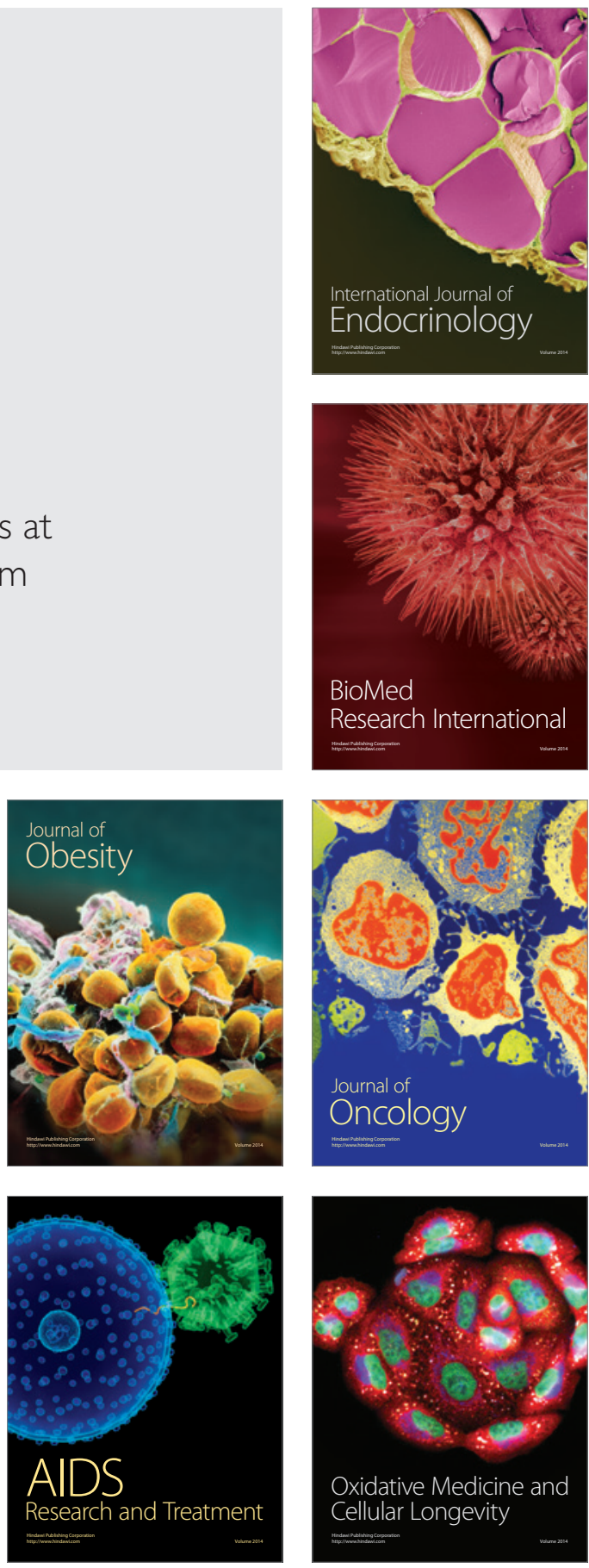